\title{
DESIGN AND FABRICATION OF MAGLEV TURBINE FOR AC POW- ER GENERATION USING FIRE
}

\author{
Rahul Gurpude ${ }^{1}$, Aishwarya Bodhankar ${ }^{2}$, Shubham Gaurkar ${ }^{3}$, TejasPatil ${ }^{4}$, Suhas Jangade \\ ${ }^{1}$ Department of Mechanical Engineering, RashtrasantTukdoji Maharaj University, Nagpur \\ ${ }^{2}$ Department of Mechanical Engineering, RashtrasantTukdoji Maharaj University, Nagpur \\ ${ }^{3}$ Department of Mechanical Engineering, RashtrasantTukdoji Maharaj University, Nagpur \\ ${ }^{4}$ Department of Mechanical Engineering, RashtrasantTukdoji Maharaj University, Nagpur \\ ${ }^{5}$ Department of Mechanical Engineering, RashtrasantTukdoji Maharaj University, Nagpur
}

\begin{abstract}
The paper depicts a system which has used the unwanted and waste heat energy as a source of renewable energy for the production of electricity. This heat energy can be used for the production of alternating current, with the help of an AC turbine. The absorbed heat will be used to generate steam using condenser which works as the de-condenser. The turbine works on the concept of magnetic levitation for the production of current. This following work can change the present scenario of power production and distribution, also making optimum and efficient use of energy. Following project can be used for domestic as well as for industrial application.
\end{abstract}

Keywords -Waste Heat Chamber, AC Turbine, Condenser, Magnetic Levitation, De-condensation

\section{INTRODUCTION}

There are many non- conventional energy resources available in our surrounding that can be used economically in order to produce electricity. But to fetch these resources and making their best use includes a lot of wealth, time and effort which means to harness the energy and to store it is the main big challenge that ultimately increases the overall cost of the plant. There is a release of huge amount of energy in the form of heat that comes in the list of waste products. It may be in the form of unused heat from boilers, chimneys or the household gas stoves. This project deals with this heat energy that can be used for increasing the rate of electricity production and distribution, so that even the rural areas are benefited. As we know that many small villages in India are still part of the dark zones this project can be considered the most beneficial for such areas. Moreover the turbine used works on magnetic levitation principle and gives directly an AC current output. The AC turbine is expected to increase the hierarchy of upcoming technology that uses maglev. This is a kind of mini power plant that can be installed for the power generation. From the industrial point of view, the output of the entire power plant can be increased.

\section{PRINCIPLES USED}

Magnetic levitation is a concept wherein the objects can be suspended against one another without any support. The overall effects of the gravitational forces are counteracted by the electromagnetic forces. Maglev is a combination of two laws which produces the desired suspension. Maglev is basically based on two simple and fundamental laws of electromagnetism.

\subsection{Faraday's Law}

It states that: "The emf (electromagnetic force) induced in a circuit is directly proportional to the time rate of change of magnetic flux through the circuit."

$$
\mathcal{E}=-\frac{d \Phi_{B}}{d t}
$$

$\mathcal{E}$ is the electromagnetic force (EMF) in volts $\Phi B$ is the magnetic flux through the circuit (in Webers).

\subsection{Lenz Law}

It states that: "Induced electromotive force generates a current, which flows in such direction as to induce a counter magnetic field that opposes the magnetic field generating the current". It basically gives the direction of the induced emf.

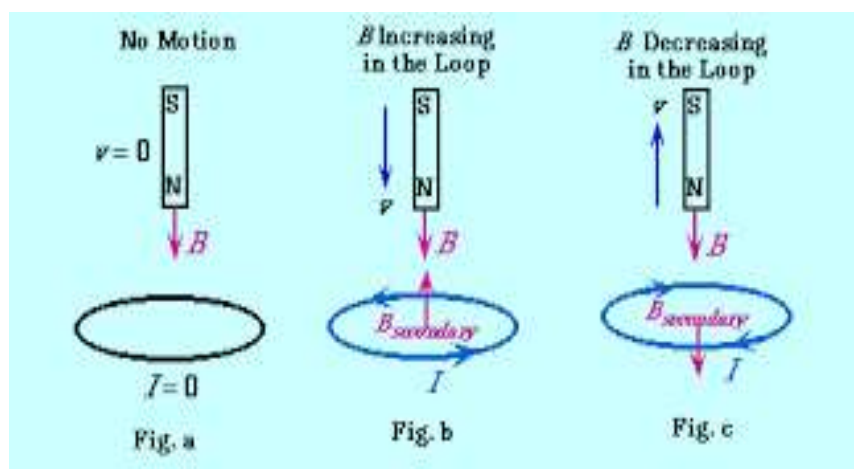

Fig 1 Direction of the induced emf. 


\section{METHODOLOGY}

The whole system can be classified into three parts according to the variation of the processes.

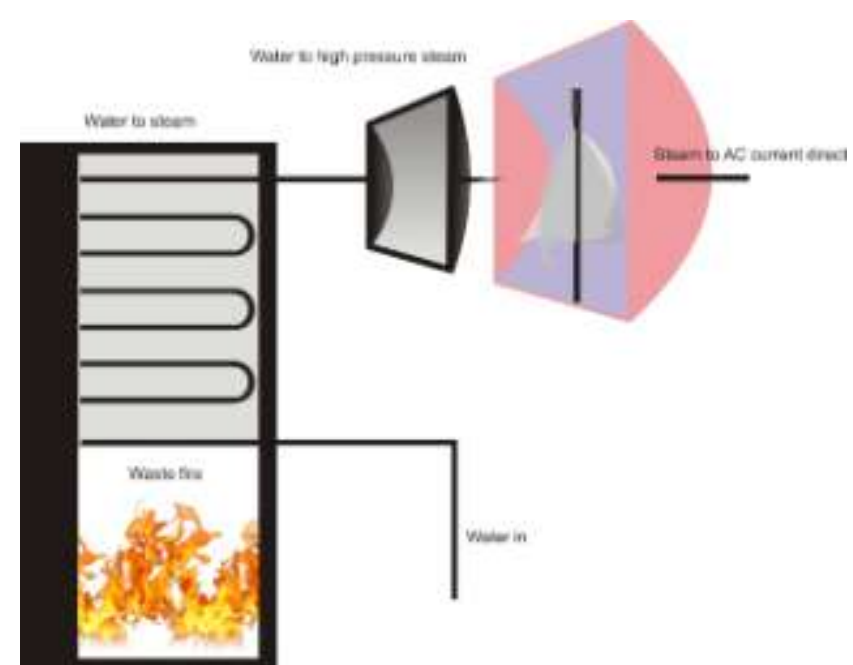

Fig 2 Block Diagram of the System

With the help of the figure the entire system and its working can be easily understood. We have a chamber which basically consists the waste fire or the waste heat energy. This chamber signifies the heat that comes under wastage part. It may be the unused heat from the chimney or the fire flames which are not utilized to their efforts. In this chamber any material can be used as a source of fire and heat. This entire chamber is attached to a unit called the condenser that works for the de-condensation of water. There is water inlet provided and this water need not be just distilled water it may be normal water as well. The steam so produced will be fed to the diffuser wherein the velocity of the steam will be increased so that when it hits the blades of the turbine we get our necessary AC current output. When the blades rotate using maglev the friction content is reduced to zero and more efficient output is given out.

\subsection{Condenser}

The condenser is supplied with the water inlet from its one end. This water used may or may not be of high quality. The condenser consists of copper tubings which are a kind of pipes through which the water will pass. We have used copper material because of its ductility, good conduction of electricity, temperature and heat.

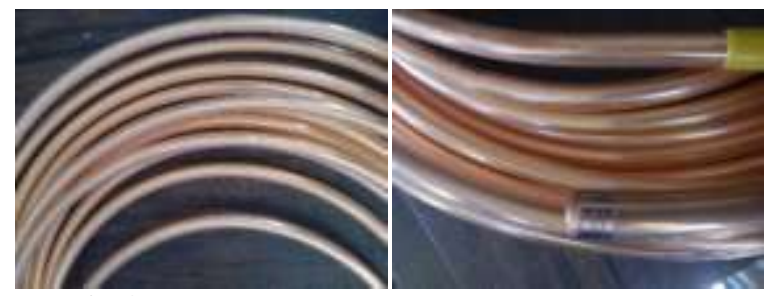

Fig 3 Copper Tubings Used In the Condenser.

De-condensation actually means a loosening of the texture of chromatin but here we are talking about the phase change of the substance from liquid to vapor and hence we have used this word for the process accomplished by condenser. Due its material the ease of conversion of phase can be achieved. The steam generation occurs at a temperature equivalent to water's boiling point. This generated steam will be further fed to the diffuser and then ultimately to the AC turbine for giving the ultimate output of electricity. After the condenser there is a pressure vessel that is placed in order to produce the necessary pressure to the steam so that it can rotate the turbine with the desired pressure. This pressure vessel not only imbibes the required pressure to the steam but also provides a certain amount of velocity.

\subsection{AC Turbine}

The steam from the diffuser hits the blades of the turbine due to which there is conversion of energy from potential energy to kinetic energy. The heart of the turbine are its magnets which bring about the frictionless power generation with zero losses in it, based on maglev. The magnets used are neodymium magnets which are the world's strongest magnets which bring about the phenomenal concept of maglev very efficiently. Moving ahead we have a shaft below which there is a circular disc.

Table 1: Specifications of Shaft

\begin{tabular}{|l|l|}
\hline Type & Ring magnet \\
\hline Diameter & $19 \mathrm{~mm}$ \\
\hline Height & $300 \mathrm{~mm}$ \\
\hline Id & $20 \mathrm{~mm}$ \\
\hline
\end{tabular}

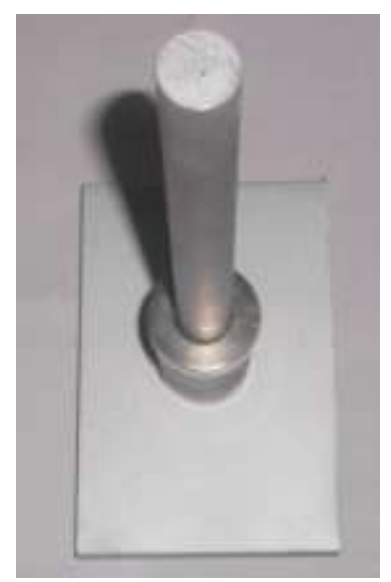

Fig 4 Shaft and DiscDesign

The disc at the base is of ring magnet and is made up of transparent material for the ease of any technical issue. Moreover the thickness of the material is so selected that the stiffness and less weight is maintained. The centre hole is given the specification of $20 \mathrm{~mm}$ so as to produce zero friction and still rotate with balance.

Table 2: Specifications of Disc

\begin{tabular}{|l|l|}
\hline Type & Ring magnet \\
\hline Thickness & $3 \mathrm{~mm}$ \\
\hline Centre hole & $20 \mathrm{~mm}$ \\
\hline Diameter & $300 \mathrm{~mm}$ \\
\hline
\end{tabular}


The turbine has copper coils of a number of turns which are wound in order to produce the emf used for the power generation. There are total of 12 different groups of such copper coils within the turbine.

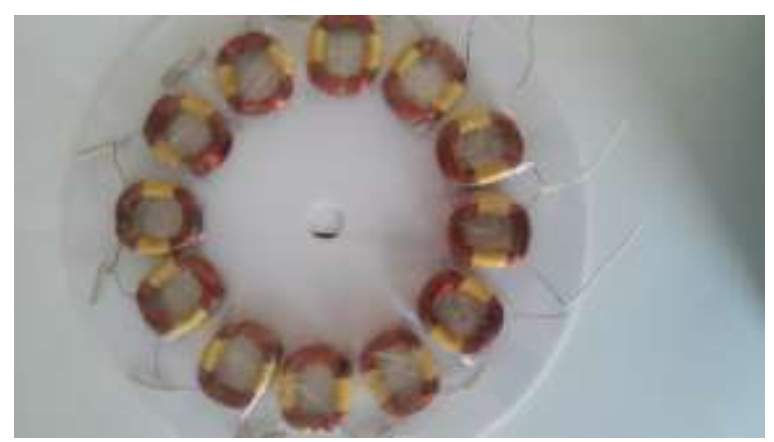

Fig 5 Copper Windings of the AC Turbine

Lastly we have the blades. We have used GI as the material for the blades because it is easy to mold and moreover it has a better strength than aluminum and steel. Due to these dual factors we found it to be the best material for our blades considering the use and working conditions of the blades.

Table 3: Specifications of Blades

\begin{tabular}{|l|l|}
\hline Material & GI \\
\hline Height & $380 \mathrm{~mm}$ \\
\hline Width & $250 \mathrm{~mm}$ \\
\hline Thickness & $1 \mathrm{~mm}$ \\
\hline
\end{tabular}

\section{CONCLUSION}

Magnetic Levitation is an important aspect for achieving many future goals and coming up with new innovative technologies. One of the most important factor to be considered in the project is to make use of the waste material and bringing it to use for power generation and ultimately producing AC output. With minimum quantity of input feeding we tend to achieve maximum output, with less number of components, all operating to their fullest strength.

\section{REFERENCES}

[1]. Mayer, D., Magnetic levitation and it's applications, in Czech, ELEKTRO 1/2003,pp. 4-12

[2]. Jayawant, B.V., Electromagnetic levitation and suspension techniques, Edward Arnold, London, 1981.

[3]. Sinha, P.K., Electromagnetic suspension - Dynamics and control, Peter Peregrinus, London, 1987.

[4]. Moon, F.C., Superconducting levitation - Applications to bearings and magnetic transportation, John Wiley\&Sons, New York, 1994.

[5]. Geim, A.K.; Simon, M.D.; Boamfa, M.I. \&Hefflinger, L.O., Magnetic levitation at your fingertips, Nature, Vol.400, 1999, pp.323-324

[6]. Berry, M.V. \&Geim, A.K., Of flying frogs and levitrons, Eur.J.Phys.18, 1997, pp.307-313

[7]. Hull, J.R., Superconducting bearings, Superconducting Science and Technology 13, 2000, pp. R1-R15
[8]. Earnshaw, S., On the nature of the molecular forces which regulate the constitution of the luminferous ether., Trans.Camb.Phil.Soc., 7, 1842, pp 97-112

[9]. Genta, G.; Delprete, C. \&Rondano, D., Gyroscopic Stabilization of Passive Magnetic Levitation, Meccanica 34, Kluwer Academic Publ., 1999, p.411-424 28

[10]. www.renevableenergyindia.com 